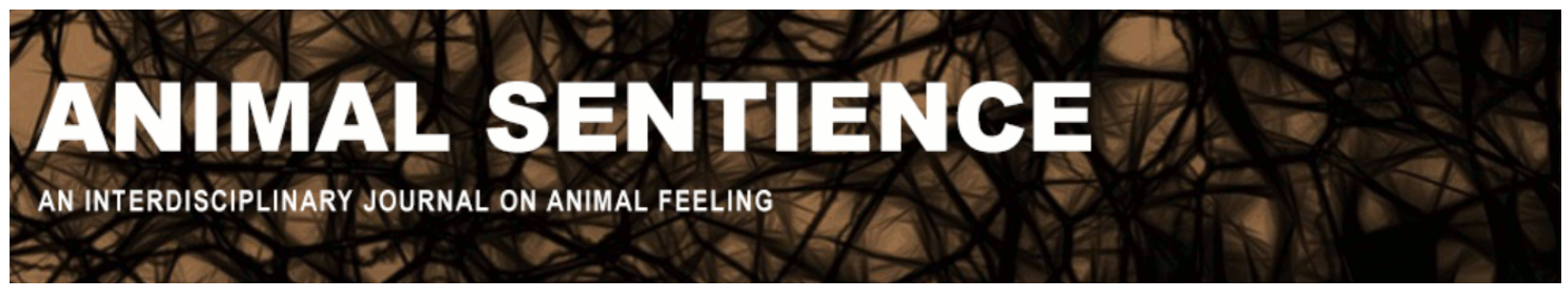

Colombo, Matteo (2018) How to foster respect for animals? Superiority, dissimilarity, and prejudice. Animal Sentience 23(9)

DOI: $10.51291 / 2377-7478.1383$

Date of submission: 2019-01-26

Date of acceptance: 2019-02-06 (c) 


\title{
How to foster respect for animals? \\ Superiority, dissimilarity, and prejudice
}

Commentary on Chapman \& Huffman on Human Difference

\author{
Matteo Colombo \\ Tilburg Center for Logic, Ethics and Philosophy of Science \\ Tilburg University, The Netherlands \\ Humboldt Research Fellow at Department of Psychiatry and Psychotherapy \\ Charité - Universitätsmedizin Berlin, Germany
}

\begin{abstract}
Chapman \& Huffman ( $C \& H$ ) might be taken to argue as follows: Humans may treat animals however they want only if humans are superior to animals. But humans are not superior to animals. Therefore, humans may not treat animals however they want. Whatever its merit, this is not C \& H's actual argument. Their point, instead, is that humans often mistreat animals because they tend to perceive them as inferior. A remedy for animal mistreatment would then be acknowledging the deep similarities between us and animals. But is C \& H's suggested remedy likely to be effective to foster respect for animals?
\end{abstract}

\begin{abstract}
Matteo Colombo works in the philosophy of science, philosophy of the cognitive and brain sciences, and moral psychology. $\mathrm{He}$ is interested in the foundations of theoretical neuroscience, and more generally, in how resources from computational cognitive neuroscience can help us address philosophical puzzles about mind and morality. Website
\end{abstract}

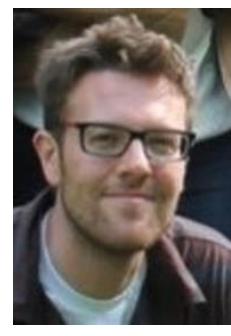

Humans possess a distinctive "norm-hungriness", an idiosyncratic need or desire to create and abide by a multitude of social norms (Colombo 2013, 2016). Courtesy of language and other external structures that allow humans to objectify their thoughts, norm-hungriness promotes an explosion of norms, leading to the creation of cognitive niches, such as legal systems, churches, and schools, which ensure that certain norms are passed on to future generations, and get updated or eliminated. Even if I'm right that norm-hungriness is uniquely human, nothing follows about whether humans are superior to other animals.

In turn, whether humans are in some respect superior to other animals doesn't entail that humans are justified in treating animals any way we want. In How to Count Animals, More or Less, for example, Kagan (in press) articulates a hierarchical approach to moral status, in which humans have higher moral status than other animals (and different animals have higher or lower moral status than others). On Kagan's (forthcoming) hierarchical view, psychological capacities necessary to have "deep relationships", "more sophisticated and advanced knowledge", "more significant achievements" and an "ability to act out of moral conviction" (Ch. 
5.2) determine an agent's moral status. Even if Kagan's hierarchical view is right, nothing follows about whether humans are justified to mistreat animals.

Many religious doctrines posit human superiority to animals; but they also recommend that humans treat other animals with kindness and respect. For example, in the Catechism of the Catholic Church, we read: "In God's plan man and woman have the vocation of 'subduing' the earth as stewards of God. This sovereignty is not to be an arbitrary and destructive domination. God calls man and woman, made in the image of the Creator 'who loves everything that exists', to share in his providence toward other creatures; hence their responsibility for the world God has entrusted to them".

So, let's get this straight: without further assumptions, the claim that humans are somehow unique or superior to other animals doesn't entail anything about how humans ought to treat them.

In fact, Chapman \& Huffman 2018 (C \& H) make a different point. A point that will remind some of their readers of de Montaigne's passage is in An Apology for Raymond Sebond (Book 2, Chapter 12, The Essays):

"Presumption - writes de Montaigne - is our natural and original disease. The most wretched and frail of all creatures is man, and withal the proudest... 'Tis by the same vanity of imagination that he equals himself to God, attributes to himself divine qualities, withdraws and separates himself from the crowd of other creatures, cuts out the shares of the animals, his fellows and companions, and distributes to them portions of faculties and force, as himself thinks fit".

Similarly to de Montaigne, C \& H point out that perceptions of human uniqueness have often been used for defending claims of human superiority, which, in turn, have been used for licencing cruelty to animals. "We need to acknowledge - C \& H suggest - how much we resemble them and how much we have to learn from them. Doing so will allow us to make decisions ... with a realistic understanding of the consequences of our actions, for them as well as for us". So C \& H's point as well as their suggested remedy for animal mistreatment is focused on human psychology - on the similarities between humans and other animals. But is there reason to believe $C$ \& $H^{\prime}$ 's suggested remedy is generally effective?

One of the most robust findings in social psychology is the association between perceiving a group as having a dissimilar worldview and having negative attitudes towards members of that group (Byrne 1969). While this association may prompt intolerant behaviour towards outgroups, social psychologists have identified various ways to reduce prejudice - for instance, by promoting interaction and contact between members of different groups, by creating a common goal, and, indeed, by highlighting similarities between groups (e.g., Dovidio \& Gartner 1999; Pettigrew \& Tropp 2006).

Prejudice towards human outgroups seems to be related to prejudice towards other animals (Plous 2003; Hodson \& Costello 2012). Beliefs that animals and humans are similar have been found to be associated with more positive attitudes to human outgroups, while "seeing humans as different from and superior to animals plays a key role in animalistically 
dehumanizing human outgroups ... and negatively evaluating those outgroups" (Dhont et al., 2014, 105).

So findings in social psychology give us reason to believe $\mathrm{C} \& \mathrm{H}^{\prime} \mathrm{s}$ suggested remedy is likely to be effective. In some domains, however, it may be more effective to try and break the link between dissimilarity and prejudice without altering perceived dissimilarities between animals and humans. After all, fostering perceptions of similarity may be unfeasible and even counterproductive in some domains - for example, in domains involving certain religious or political beliefs, or eating practices to which many humans are committed and would not give up without opposition.

Similarly, repeating that we have common goals like the conservation of the world's ecosystems, which may highlight similarities between humans' and animals' interests, may not be the most effective option in the political domain, where humans with different political values have fundamentally different views about how ecosystems should be preserved. Here emphasising the similarities in the interests of humans and animals may motivate reactionary responses.

Long-term, structural interventions aimed at breaking the association between dissimilarity and prejudice, without altering perceived dissimilarities between animals and humans, could be focused on cultivating personality traits like intellectual humility, or on puncturing humans' illusion of explanatory depth (Voelkel, Brandt, \& Colombo 2018). If humans realize - through education, trustworthy sources of information, respected role models, or scientific contributions like C \& H's - that they know much less about other animals' lives, mental capacities, and behaviour than they initially assume, then they will question the basis for their speciesism. Once we understand we know very little about other animals, we will learn to treat them with respect and humility.

\section{References}

Byrne, D. (1969). Attitudes and attraction. Advances in Experimental Social Psychology, 4, 35-89. Chapman, C. A., \& Huffman, M. A. (2018) Why do we want to think humans are different? Animal Sentience 23(1).

Colombo, M. (2013). Leges sine moribus vanae: Does language make moral thinking possible?. Biology \& Philosophy, 28(3), 501-521.

Colombo, M. (2016). Animal grieving and human mourning. Animal Sentience 4(10).

De Montaigne, M. (2003). The Complete Works: Essays, Travel Journal, Letters. Ed. and trans., D. M. Frame. New York: Everyman's Library.

Dhont, K., Hodson, G., Costello, K., \& MacInnis, C. C. (2014). Social dominance orientation connects prejudicial human-human and human-animal relations. Personality and Individual Differences, 61, 105-108.

Dovidio, J. F., \& Gaertner, S. L. (1999). Reducing prejudice: Combating intergroup biases. Current Directions in Psychological Science, 8(4), 101-105.

Hodson, G., \& Costello, K. (2012). The human cost of devaluing animals. New Scientist, 2895, 3435.

Kagan, S. (in press). How to Count Animals, More or Less. Oxford: Oxford University Press. 
Pettigrew, T. F., \& Tropp, L. R. (2006). A meta-analytic test of intergroup contact theory. Journal of Personality and Social Psychology, 90(5), 751-783.

Plous, S. (2003). Is there such a thing as prejudice toward animals? In S. Plous (Ed.), Understanding Prejudice and Discrimination (pp. 509-528). New York: McGraw-Hill.

Voelkel, J. G., Brandt, M. J., \& Colombo, M. (2018). I know that I know nothing: Can puncturing the illusion of explanatory depth overcome the relationship between attitudinal dissimilarity and prejudice? Comprehensive Results in Social Psychology, 3, 56-78. 